\title{
Sangradores Africanos na Bahia do Século XIX (1825 - 1828)
}

\author{
Jacimara Souza Santana ${ }^{1}$ \\ Andreilza Oliveira dos Santos ${ }^{2}$
}

\begin{abstract}
Resumo: Na primeira metade do século XIX, precisamente entre os anos de 1825 e 1828 , o ofício de sangrador assume um papel importante no exercício das práticas de cura. Esses atores prestaram serviços de saúde junto à população baiana, mediante a concessão de licenças de um órgão do governo colonial chamado Fisicatura-Mor (1808 a 1828). Este artigo apresenta uma abordagem inicial sobre a atuação dos sangradores africanos - sobretudo a população trazida de diferentes lugares da África, na condição de escravos - na assistência de saúde à sociedade baiana. As más condições da travessia do Atlântico durante o tráfico acometeram essa população de um agravamento dos problemas de saúde e de uma elevada mortalidade. A esta situação somou-se a carência de assistência em saúde prestada por proprietários de escravos ou pelo governo. Para apreender as iniciativas dos sangradores africanos, utilizamos como fontes autos de exame, cartas de licença, relatórios de inspeção e cartas de embarcações.
\end{abstract}

Palavras-chave: História, saúde, medicina, sangrador.

Abstract: In the first half of the nineteenth century, precisely between the years 1825-1828, the office of bleeder played an important role in the performance of healing practices. These actors have provided health services near the population of Bahia through the licensing of a government agency called colonial FisicaturaMor (1808-1828). This article presents an initial approach on the performance of the bleeders in the African health care to Bahian society, especially the people brought from different parts of the continent on the condition of slaves. The poor condition of crossing the Atlantic during trafficking affected this population to a worsening of health problems and high mortality. In this situation, summed up the lack of health care provided by slave owners or government. To seize the initiatives of African Bleeders used as sources: records of test cards, license, inspection reports and letters of vessels.

Key-Words: History: Health: Medicine: Bleeder

\section{INTRODUÇÃO}

A Bahia, na primeira metade do século XIX, foi palco para a atuação de diversos profissionais nas artes de curar. Os sangradores, indivíduos que ministravam saberes e práticas de cura à população, tinham seus serviços regularizados por um órgão do governo, a Fisicatura-Mor ${ }^{3}$. Este órgão incluiu os cargos de Físico e Cirurgião-Mor. Ao primeiro competia fiscalizar o ensino e o exercício dos médicos e curandeiros, bem como as medicações vendidas nas boticas. Ao segundo cabia fiscalizar o ensino e o exercício dos cirurgiões, sangradores, parteiras, dentistas e algebristas. Essa instituição, que já existia em

\footnotetext{
${ }^{1}$ Mestra em História Social, prof. de História da África da UNEB e orientadora do Projeto Qualificando a Permanência de Estudantes Cotistas SEPROMI/CEPAIA/UNEB jacimaras@yahoo.com.br

${ }^{2}$ Graduanda do Curso de Licenciatura Plena em História pela Universidade do Estado da Bahia-UNEB e bolsista de iniciação científica pela SEPROMI/CEPAIA/UNEB andreilza.O@hotmail.com

${ }^{3}$ Este órgão foi responsável por autorizar e regulamentar tais ofícios, concedendo a licença para a devida atuação em áreas específicas.
} 
Portugal desde o século XVI, foi substituída posteriormente pelo nome de Proto-Medicato, no século XVII.

Entre os diversos atores que estiveram envolvidos nos serviços de saúde, o oficio de sangrador se caracterizava como uma atividade importante, uma vez que este atuava diretamente com técnicas de cirurgia. Pesquisas já demonstraram que as condições morais, sociais e de vida enfrentadas, desde a travessia até o estabelecimento na diáspora brasileira, tornavam os africanos vulneráveis a uma série de doenças, de modo que a deficiência em saúde nesta população constituía um grave e alarmante problema. $\mathrm{Na}$ Bahia, ao longo do século XIX, os africanos e seus descendentes formaram o maior contingente populacional, especialmente em Salvador, e a quantidade de mortes entre os escravos permaneceu alta durante todo o período ${ }^{4}$.

A situação era tão gritante neste sentido que na literatura dos séculos XIX e XX não é raro encontrar visões sobre os povos africanos como agentes de doenças e epidemias. A título de ilustração, pode ser citada a produção do funcionário real e FísicoMor Manoel Vieira da Silva ${ }^{5}$, que, em resposta à solicitação do Príncipe Regente D. João VI, escreveu em 1808 um documento sobre as causas das doenças que assolavam o país e como tratá-las, a fim de reduzir a sua incidência ou até mesmo erradicá-las.

Atendo-se mais precisamente à cidade do Rio de Janeiro, Vieira da Silva argumentou que "entram neste porto navios carregados de pretos, e entrarão daqui em diante de muitos outros portos, donde nos podem provir os germes de moléstias epidêmicas". Ademais, as epidemias chegariam com os africanos não somente pelos portos, mas também pelos peitos das amas-de-leite. Havia ainda uma série de problemas sanitários da cidade, como a exposição do lixo e valas, a má localização dos cemitérios, a falta de remédios e a má qualidade da alimentação, que chegava a ser vendida em estado de putrefação. Os alimentos em mal estado de conservação eram comprados pelos senhores para serem fornecidos especialmente aos escravos, tendo em vista maximizar seus lucros com menor investimento ${ }^{6}$.

${ }^{4}$ COSTA, Emília Viotti. Da Senzala a Colônia. 3 ed. São Paulo: Brasiliense, 1989. p. 264-266; REIS, João José. "A Bahia de 1835: sociedade e conjuntura econômica". In: Rebelião escrava no Brasil: a história do levante dos Malês em 1835. São Paulo: Companhia das Letras, 2003. p. 19-43; SILVA, Op. cit. p. 78.

5 Manoel Vieira ocupou o cargo de Físico-Mor do Reino entre os anos de 1753 e 1823.

${ }^{6}$ SILVA, Manuel Vieira da. Reflexões sobre alguns dos meios propostos por mais conducentes para melhorar o clima da cidade do Rio de Janeiro. 1808. Impressão Régia. 1808. 
Para Vieira da Silva, a atenção à saúde pública na colônia exigia de Vossa Alteza executar medidas julgadas indispensáveis. Era preciso investir em um serviço policial nos portos, cuja responsabilidade seria averiguar as ameaças de epidemias nas embarcações ali aportadas, assim como construir Casas de Saúde, os chamados Lazaretos, para onde pudessem ser encaminhados "os pretos" para a quarentena, até que recobrassem o "perfeito estado de saúde". Além disso, providenciar remédios de qualidade e investir em um maior controle das práticas dos curandeiros e curandeiras, cirurgiões e boticários. $\mathrm{O}$ parecer sobre as condições de saúde das demais cidades portuárias do país não se diferenciava muito desta análise apresentada por Manoel Vieira da Silva. Uma consulta parcial aos documentos da Fisicatura-Mor e Provedoria- Mor da Bahia, referentes à primeira metade do século XIX, mostra uma preocupação relevante com as questões sanitárias citadinas, incluindo os cemitérios, a fiscalização da venda de alimentos e matadouros, assim como o policiamento nas embarcações ${ }^{7}$.

Outros autores, como José Pereira do Barão do Lavradio Rego e Octávio Freitas, também comungaram da hipótese de que os povos africanos fossem uma fonte ambulante de morbidades e veículo das epidemias introduzidas na colônia. Para Rego (1872), as epidemias de varíola e febre amarela teriam se constituído numa das maiores causas de perturbações sanitárias no Brasil, cuja responsabilidade de contaminação era dos africanos. Pensamento similar pode ser encontrado na obra de Octávio Freitas, em seu livro Doenças dos Africanos no Brasil, escrito em 1935. De acordo com Freitas, um dos maiores desconcertos sanitários foi o processo de povoação e civilização do Brasil alavancado pelos colonizadores, em especial no que diz respeito aos povos africanos, responsáveis pela importação de toda sorte de doenças que vieram a assolar o país. Para esta constatação é evidente que não são levados em conta os fatores que envolveram as condições de tráfego

\footnotetext{
${ }^{7} \mathrm{O}$ diagnóstico que imputava aos povos africanos a responsabilidade da origem das epidemias não foi o único. Luis Otávio Ferreira mostra em sua análise dos periódicos médicos da primeira metade do século XIX que no parecer de diferentes médicos portugueses, como também do francês José Francisco Xavier Sigaud, os fatores climáticos, as condições sanitárias (distribuição do lixo, valas, cemitérios etc.) e em especial a topografia da cidade, no caso do Rio de Janeiro, apareciam como fatores relevantes para a difusão de doenças por meio da contaminação da atmosfera. FERREIRA, Luis Otávio. Os periódicos médicos e a invenção de uma agenda sanitária para o Brasil (1827-43). Hist. Ciênc. Saúde - Manguinhos, vol 6. nº 2. Rio de Janeiro, jul-out. 1999.
} 
e, muito menos, os fatores relacionados à interação de povos que se misturaram em determinado ambiente ${ }^{8}$.

Associado a estes fatores, nesse período a assistência pública em saúde para esses povos e população, de modo geral, era bastante precária. A carência de assistência médica na colônia era algo não resolvido e que também atingia a pessoas livres e pobres. Ao longo do século XIX, mesmo após a criação das faculdades de medicina, o atendimento médico, de uma maneira geral, era bastante carente. O serviço de saúde caracterizava-se pelo atendimento domiciliar, ou seja, de caráter privado. Nesse período, as rezas, as receitas de chá e os manuais de saúde, alguns específicos para cuidar das doenças dos "escravos", foram recursos bastante utilizados. As Santas Casas de Misericórdia também ofereciam atendimento particular, acolhendo reduzido contingente da população escrava somente em casos extremos. Diferentes pesquisas mostram que os serviços de saúde, tanto no período colonial quanto no imperial, ficavam mais a cargo dos curandeiros, benzedores, sangradores e cirurgiões ${ }^{9}$.

Para o Físico-Mor Manoel Vieira da Silva, já mencionado acima, o investimento no cuidado da saúde dessa população enquanto escravo (a) encareceria o seu preço e traria, consequentemente, uma diminuição deste comércio. Silva, contudo, reconheceu que as condições de saúde da população africana denunciavam uma "omissão de providências". Para ele, esta situação ainda expunha a ideia de que “o príncipe regente Nosso Senhor se interessava mais pelo aumento dos brancos, sejam brasileiros ou europeus, do que pela propagação dos pretos"; e reafirmava que a perda com a diminuição do comércio ainda seria menor do que os efeitos desta omissão. Provavelmente, referia-se aos perigos de epidemias que essa situação poderia gerar.

\footnotetext{
8 REGO, José Pereira do Barão do Lavrado. 1816-1892. Nota suscinta sobre as condições geraes da salubridade do império feita em 1872; Freitas, Octávio de. Doenças Africanas no Brasil. São Paulo: Companhia Editora Nacional, 1935.

9 COSTA, Emília Viotti. Da Senzala a Colônia. 3 ed. São Paulo: Brasiliense, 1989. p. 266; BERTOLLI FILHO, Cláudio. História da Saúde Pública no Brasil. São Paulo: Ática, 2001. p. 5-7; SAMPAIO, Gabriela dos Reis. Nas Trincheiras da Cura: as diferentes medicinas no Rio de Janeiro imperial. São Paulo: Unicamp, 2001; FERREIRA, Luis Otávio. Os periódicos médicos e a invenção de uma agenda sanitária para o Brasil (1827-43). Hist. Ciênc. Saúde - Manguinhos, vol 6. no 2. Rio de Janeiro, jul-out. 1999; PÔRTO, Ângela. O sistema de saúde do escravo no Brasil do século XIX: doenças, instituições e práticas terapêuticas. História, Ciências, Saúde - Manguinhos, vol 13. n ${ }^{\circ}$ 4. Rio de Janeiro, out.-dez. 2006, p. 1019-27; DEBRET, Jean Baptiste. Viagem Pitoresca e Histórica ao Brasil. Tradução e Notas de Sérgio Millet. Tomo I (vol I e II). Terceira edição. São Paulo: Livraria Martins Editora, 1954. p. 152.
} 
A condição escrava seria o suficiente para explicar esta falta de assistência? Afinal, perder escravos e escravas também não equivaleria a prejuízo econômico? De fato, na lógica empresarial do tráfico os povos africanos eram percebidos como produtos destinados a venda e compra. E, ao que parece, a qualidade do produto negociado não estava circunscrita aos rendimentos desse comércio, apesar da aparência ser um critério importante no ato da compra. No entanto, conforme argumentos do Físico-Mor Manoel Vieira da Silva, a falta de assistência dispensada a esta população constituía uma ameaça à saúde de outros segmentos populacionais, inclusive o da família real e sua comitiva, que chegaram ao Brasil em 1808, que passaram a integrar essa população a partir de 1808.

Luis Oliveira Mendes defendia que a morbi-mortalidade que acometia os povos africanos traficados para o Brasil resultava dos maus tratos. Mendes afirmava: "todo o estrago, e mortandade mais se deve aos maus tratos, e ao desamparo, a que são entregues, do que ás muitas enfermidades, e moléstias”. Segundo ele, todas as doenças que atingiam os povos africanos, até mesmo o banzo, não eram desconhecidas entre eles, e, por isso mesmo, eram tratáveis. Os próprios africanos as conheciam e desenvolviam formas de tratamento para as mais diferentes doenças. Isto foi o que pôde observar na "Costa da África" ${ }^{10}$.

Mendes constatou que a assistência era negada a esses povos em consequência do extremo cuidado que os traficantes e proprietários tinham com seus lucros. Para o autor, a medicina não era tão carente de conhecimento que não pudesse tratar de certas doenças que atingiam esses povos, pois, ainda com dificuldades, quando se tratava de pessoas brancas, estabelecidas e ricas, eram convocados professores de medicina a tempo, e estas eram curadas. Se havia raridade de médicos e desconhecimento das doenças e de como tratá-las, por que não se buscava adquirir esses conhecimentos e aprender com os próprios africanos, através de seus intérpretes? ${ }^{11}$

Prossegue Mendes afirmando que a eficácia das práticas terapêuticas africanas foi comprovada por D. Francisco Inocêncio, governador da cidade de S. Paulo, no Reino

\footnotetext{
10 OLIVEIRA MENDES, Luis Antônio de. Determinar com todos os seus sintomas as doenças agudas e crônicas que mais frequentemente acometem os pretos recém-tirados da África; examinando as causas da mortandade depois da sua chegada ao Brasil, se talvez a mudança do clima, se a vida mais laboriosa, ou se alguns outros motivos concorrem para tanto estrago; e finalmente indicar os métodos mais apropriados para evitá-lo, prevenindo-o, e curando-o; tudo isto deduzido da experiência mais sisuda e fiel. (Premiado na sessão pública de 12 de maio de 1793).

11 OLIVEIRA MENDES, Op cit. p. 57-62.
} 
Unido de Angola. Este testemunhou os "efeitos tão prodigiosos" do tratamento de carbúnculo utilizado pelos africanos, levando não somente a receita para Portugal, mas também o quicongo e a folha da pita. Outra testemunha mencionada por Mendes foi Raimundo Jamalá, que habitou em Luanda entre 1750 e 1770. Durante o seu trabalho com o tráfico no continente, utilizou o saber médico africano para cuidar dos escravos em sua posse. Embora o investimento encarecesse o seu preço, os escravos gozavam de perfeita saúde. Por fim, Mendes propõe que entre os africanos pudessem ser designados alguns para o cuidado da saúde dos demais.

Diante do exposto, cabe ainda perguntar como esse problema de maior vulnerabilidade dos povos africanos teria sido tratado pela política de saúde pública no período. É neste contexto de agravo de doenças, mortandade e falta de assistência que os sangradores atuaram como atores importantes no cenário do século XIX. Seus serviços eram oferecidos tanto em terra quanto nas embarcações dos navios negreiros, e talvez atuassem como essenciais, em especial, para as necessidades da população africana. Supõese o desempenho desses atores como importante no processo da construção de um sistema de saúde que se formava no século XIX. Desta maneira, existe a necessidade de estudos mais específicos sobre o assunto.

O tráfico contribuiu para a vinda de povos africanos de diversas nações ${ }^{12}$, e com estes, suas visões de mundo, culturas, línguas, religiões, saberes e práticas de cura, entre outras coisas. Nessa perspectiva é preciso levar em consideração a incidência de doenças que acometiam esta população e perceber como se dava a atuação e a contribuição destes povos no trato das mesmas. Também se faz necessário atentar para o fato de que a medicina africana na Bahia era um conjunto de concepções e práticas de cura resultante da interação de medicinas africanas de diferentes nações. São denominados Minas a maioria dos sangradores registrados nos livros de exame baianos. Além disso, deve ser levada em consideração também a sua interação com práticas médicas indígenas e, em especial, européias, em virtude de que a legalização das práticas de cura dos povos africanos pelo Estado colonial exigia essa aproximação com o modelo ocidental.

\footnotetext{
12 Segundo Luis Nicolau Parés, a denominação "nação" era uma forma de classificar os diversos grupos de africanos no continente e era um termo muito utilizado pelos traficantes de escravos.
} 


\title{
Considerações acerca do ofício de sangrador
}

As atividades de trabalho destinadas ao sangrador se constituíam em aplicar sanguessugas e ventosas. Estas serviriam para limpar o organismo e, consequentemente, melhorar o seu funcionamento. Eles ainda aplicavam sudoríficos, purgantes e tiravam dentes, entre outras funções. Para obter a licença de atuação no exercício da sangria era necessário passar por uma avaliação realizada pela Fisicatura-Mor, que incluía exames teóricos e práticos. Os sangradores que por ventura fossem embarcar a trabalho nos navios também deveriam solicitar licenças de viagem.

Para Tânia Salgado Pimenta, a sangria era uma técnica bastante requisitada no trato das doenças, sendo muito utilizada na Europa. Ao Brasil, chegou em meados do século XVI. É comum, ao delimitar as atividades correspondentes ao ofício de sangrador, encontrá-la associada à de barbeiro, ou até mesmo os dois termos juntos: sangradorbarbeiro ou vice-versa. No entanto, para a Fisicatura-Mor havia maiores prescrições que norteavam a execução de cada ofício:

\begin{abstract}
(...) Essa distinção servia também para deixar bem clara a diferença entre a arte de sangria e a atividade de barbeiro. A partir da quantificação dos dados pude concluir que o termo barbeiro era identificado com uma prática mais popular, cujos agentes faziam parte de um estrato social mais baixo, enquanto o termo sangrador era designado para se referir a uma arte que, apesar de menor, fazia parte da cirurgia. (PIMENTA, 1997, p.88).
\end{abstract}

Através da análise de 18 autos de exames e cartas de licença de sangradores africanos, nosso estudo mostra o quanto a arte de sangrar era um importante campo de atuação dos africanos na Bahia. $\mathrm{Na}$ análise dos dados encontramos sangradores africanos pertencentes às nações Mina (50\%), Jeje (33\%) e Angola (6\%), além de outros sem identificação (11\%). Cabe ressaltar que o campo de atuação de tais profissionais é extremamente amplo, o que dá margem ao desenvolvimento de diversas ocupações dentro dos serviços de saúde. É formada, assim, uma importante rede de conhecimentos e saberes predominantes, constituindo múltiplas relações entre doença, morte e cura. 


\section{Gráfico 1 - Percentual de sangradores africanos*}

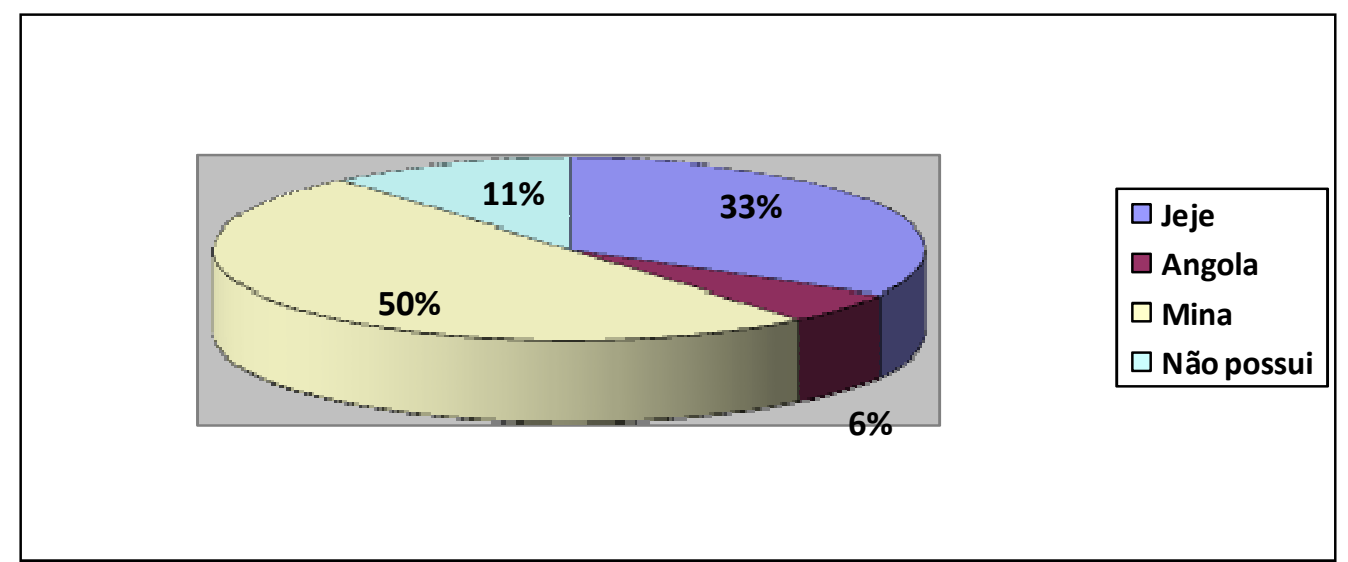

Fonte: Autos de exames e cartas de sangradores para a atuação no exercício da arte de curar. Documentação do Arquivo municipal da Bahia/Salvador 1825 - 1828.

A partir da análise dos dados da pesquisa, assim como da leitura de outras bibliografias, a exemplo da dissertação de Tânia Pimenta, constata-se como uma particularidade típica do ofício de sangrador o fato de ser um trabalho executado em sua maioria pelo público masculino. Geralmente, parte destes eram escravos ou forros que conseguiam atingir esta condição graças ao seu bom desempenho. Uma exceção a essa regra é o caso de Joanna Maria do Nascimento, da qual eram ressaltados certos conhecimentos sobre cirurgia oriundos da prática à assistência de partos. Sua licença para atuar foi concedida em agosto de 1821. Assim como no caso de Joanna Maria do Nascimento, identificamos também a sangradora Francisca Barbosa de Castro, liberta e de nação Jeje, que obteve a sua carta de licença em 1826. Tais casos evidenciam também a participação feminina em outras áreas da saúde além da arte de partejar, um ofício típico de mulheres.

\section{Os sangradores e suas particularidades na sociedade}

O ofício de sangrador se constitui como uma atividade fundamental dentro da medicina acadêmica. Era um trabalho que englobava múltiplas utilidades e conhecimentos necessários, como por exemplo, a sangria e sua aptidão para lidar com tarefas que requeriam certa agilidade motora. Segundo Betânia Gonçalves Figueiredo ${ }^{13}$, havia uma

13 Docente do Departamento de História da Universidade Federal de Minas Gerais, também é autora do livro “Arte de Curar", editora Vício de Leitura, 2002. 
hierarquização entre os membros envolvidos nos serviços de saúde, que pode ser analisada na atuação dos cuidados de saúde com o corpo, considerando a amplitude do campo de exercício, que se dividia entre sangradores, cirurgiões e médicos, entre outros.

No caso do sangrador, entende-se que este ofício tinha seu prestígio no seio da sociedade da época, uma vez que era bastante procurado pela população. No entanto, se comparado a outras profissões em termos de status, não obtém tanto espaço na pirâmide social. Esta visão pode ser compreendida ao adentrarmos a estrutura social vigente: os principais aspectos que marcam a sua composição se dão através das formas de comportamentos, como, por exemplo, a predominância de favores e a obediência, entre outros laços, que ocasionam, de certa maneira, um vínculo de proteção ou até a nomeação para cargos públicos. Algo contraditório que engloba toda a sociedade, e em tempo algum conseguira abranger a coletividade.

Havia disputas e conflitos entre os ofícios das práticas de cura. Algumas profissões ocupavam uma função de status dentro da sociedade, não sendo esse o caso do oficio de sangrador. O pensamento sobre o projeto de saúde seria concebido nas academias, ou seja, pelo conhecimento científico, o que tornava necessário mudar os costumes e práticas, de acordo com os critérios estabelecidos pela ciência. Segundo E. P. Thompson ${ }^{14}$ essas transformações com intuito de "reformar" os costumes partiam dos "superiores". Como o mesmo aponta: “(...) O povo estava sujeito a pressões para 'reformar' sua cultura segundo normas vindas de cima, a alfabetização suplantava a transmissão oral, e o esclarecimento escorria dos estratos superiores aos inferiores - pelo menos, era o que se supunha". O Conhecimento médico acadêmico se arrogava como superior. No entanto, isso não significou ausência de resistência às imposições. Pelo contrário, daí a origem de embates e conflitos.

Os serviços dos sangradores eram bastante requisitados pela população baiana. Experiência similar, na capital da Província de Pernambudo, é comentada por Sidney Chalhoub $^{15}$, em seu livro Cidade Febril - cortiços e epidemias na corte imperial, cenário no qual a relação entre trabalho médico e "terapeutas populares" causou alvoroço e divergências:

\footnotetext{
14 Ver o livro "Costumes em comum: estudos sobre cultura popular tradicional", do mesmo autor.

$15 \mathrm{O}$ fato narrado se encontra no livro de Sidney Chalhoub, intitulado "Cidade Febril - cortiços e epidemias na corte imperial". Nesta obra, o autor traça uma discussão acerca da epidemia de cólera e as mudanças no processo de modernização do Rio de Janeiro.
} 
A Academia declarou-se "profundamente horrorizada por tanto escândalo", e não é difícil entender a irritação dos esculápios da Corte com o presidente de Pernambuco. O fracasso do arsenal terapêutico da medicina alopática no tratamento da cólera - assim como da febre amarela - era patente; poucos confiavam ainda nas sangrias, purgativos, sudoríficos e vomitórios, sendo que os homeopatas faziam carreira rápida argumentando, plausivelmente, que os alopatas aceleravam a morte dos pacientes. Naquele contexto, o apoio ostensivo de uma autoridade pública a um curandeiro africano era motivo compreensível de alarme para os doutores, mas esta é apenas uma faceta da história. (CHALHOUB, 1996, p. 135).

O fato do presidente da província manifestar apoio às artes de curar de um "curandeiro" não foi visto com "bons olhos". Logo se percebe a resistência, por parte dos médicos, em aceitar contribuições da medicina popular, sendo que em tal circunstância os terapeutas populares manifestaram certo conhecimento no trato da doença, se comparados à medicina oficial naquele contexto. Essas práticas de cura foram muitas vezes também associadas à feitiçaria ou tidas como algo sobrenatural. Predominava, dessa forma, um cunho religioso e cultural mais intenso, ou seja, elas não poderiam obter o mesmo mérito que o conhecimento científico. Esta discussão pode ser percebida através da leitura da obra de Chalhoub acima citada.

Notamos que os sangradores e "curandeiros" foram perseguidos antes e depois da criação da Fisicatura-Mor, com uma diferença: após a instituição desse órgão, eram autuados aqueles que trabalhassem sem a licença. A emergência da medicina acadêmica por meio da fundação das faculdades de medicina foi outro fator agravante destas perseguições. Em 1810, quando o regimento da Fisicatura-Mor foi reformulado, o Príncipe Regente explicitou a autonomia confiada aos funcionários reais deste órgão, inclusive de seus delegados, para o exercício de sua tarefa de fiscalização. Em seu pronunciamento, a Bahia aparece como uma antiga insubordinada nos assuntos de saúde:

Eu, o Príncipe Regente, faço saber aos que o presente Alvará virem que, havendo eu creado phisico mor e Cirurgião Mor do Reino, Estado e Domínio Ultramarino por decreto de sete de fevereiro do corrente anno, com o útil fim de entenderem de tudo quanto pode concorrer para o assunto e conservação da saúde pública, fazendo desarraigar antigos e prejudiciais abusos e dando todas as providências que forem análogas e conducentes a tão importante objecto; e sendo necessário que elles tenham autoridade e jurisdição, com que possam fazer executar os seus mandados e cumprir os negócios de sua jurisdição, para que se não mallogrem as deliberações que tomarem sobre esse ramo da pública felicidade. E havendo os Senhores Reis Meus Augustos predecessores estabelecido regimentos e promulgado muitas outras ordens régias; foi-me contudo em consulta da Mesa do Desembargo do Paço, tomada sobre a representação do phisico mor, que, tendo se movido contestações entre o seu 


\begin{abstract}
delegado e a Relação da Bahia, convinha ordenar que se guardassem os regimentos: E querendo eu evitar questões de jurisdição sempre odiosas e contrárias ao socego público dos meus fiéis vassalos e a boa ordem e regular decisão dos negócios, de que muito depende a paz pública; e sendo por isto mui necessário e útil declarar a jurisdição de Phisico Mor e cirurgião Mor e dos delegados ${ }^{16}$.
\end{abstract}

Talvez um dos problemas a que Vossa Alteza tivesse se referindo dissesse respeito a um caso semelhante que se passou entre o Cirurgião-Mor do segundo Regimento da Infantaria da Bahia, Manuel Fernando Nabuco, e o "preto" Manoel Antunes Carvalho. Esse Cirurgião-Mor

\begin{abstract}
Ainda na função fiscalizadora do exercício profissional em Salvador, colheu alguns aborrecimentos. Foi assim que mandou prender o preto Manuel Antunes Carvalho, sangrador sem licença para isso. No entanto, o Governador Dom Rodrigo José de Menezes se insurgiu contra este rigorismo da Junta do ProtoMedicato, alegando ser inoportuno esse rigor, em vista da falta de gente diplomada para o exercício da medicina cirúrgica, prática de dentistas e sangradouros, havendo necessidade constante desses ofícios na Capitania. O Governador lamentava que o julgamento do comissário Manuel Fernando Nabuco só por lei pudesse ser resolvido. Em conseqüência, pediu que a relação da Capitania fosse autorizada à apelação das sentenças dos juízes comissários. Em função dessa autorização concedida pelo Governador, o cirurgião Nabuco teve que prestar mais de uma vez informações à Relação da Bahia ${ }^{17}$.
\end{abstract}

Este episódio, que se passou no final do século XVIII, em 1793, provavelmente pode não ter sido o único caso de insubordinação baiana a ocupar a burocracia jurídica colonial. A investigação deste processo pode trazer maiores explicações sobre os motivos que levaram o governador a intervir em defesa do preto Antunes. Numa sociedade em que as relações se davam de forma hierarquizada e marcada por trocas de favores, em que o negro africano era sinônimo de escravo e, ainda que fosse liberto, dificilmente usufruía de direitos, o "preto" Antunes aparentemente mostrava ter vantagens, e foi o governador quem se pôs em sua defesa. Esta atitude não teria sido uma forma de gratidão a Antunes pelos serviços médicos prestados a ele e sua família? Conforme afirmou Tânia Salgado Pimenta, negros escravos ou livres utilizavam a medicina popular para cuidar de membros

${ }^{16}$ BARBOSA, Cássio e Plácido. Op. cit, p. 4.

17 PEDROSA, Manoel Xavier de Vasconcelos. "O Cirurgião-Mor do 2 ${ }^{\circ}$ Regimento de Infantaria da Bahia, Manoel Fernando Nabuco". In: Problemas de Medicina Militar. Academia Brasileira de Medicina Militar. II vol. Rio. 
da classe dominante não só pela falta de médicos, como pela reconhecida competência. Outro fator significativo que casos como este indicam é que os(as) africanos(as) e seus descendentes tiveram uma atuação pertinente na área da saúde ${ }^{18}$.

\section{As viagens nos navios negreiros: experiências de riscos e perigos}

A atuação de sangradores nos navios negreiros era um serviço bastante requisitado e apresentava riscos nas suas várias etapas. Segundo Manolo Florentino ${ }^{19}$, diversos aspectos foram contribuindo gradativamente para a incidência de mortes a bordo, sobretudo dos povos africanos. Por exemplo: as precárias condições alimentares, a escassez de água, a superlotação, os maus tratos, as moléstias que debilitavam e até mesmo a condição de se encontrarem enquanto prisioneiros, algo que poderia alterar a sua forma de comportamento emocional.

Outro fator concorrente à condição de perigo destas viagens diz respeito ao fato de ocorrerem, no percurso dos navios, roubos e naufrágios. Ao analisar os termos de visita às embarcações ${ }^{20}$, foi possível notar quão demorado poderia ser o percurso de viagem em alto mar, o que ocasionava consideravelmente a incidência de mortes:

Termo de visita dada no Bergantim Altar da Nuestra vinda da Costa da Mina

Aos 11 de abril 1829 annos nesta Cidade da Bahia, bordo do Bergantim Altar da Nuestra vindo da Costa da Minha pela Ilha de Príncipe com 906 dias de viagem daquele mestre de navio João de Alves Lima com carga de 807 cativos vivos e 70 mortos (...).

Termo de visita dado no Bergantim Cerco vindo da Costa da Mina

Aos 05 de março de 1827 annos nesta Cidade da Bahia, a bordo do Bergantim Cerco vindo da Costa da Mina em diretiva com 45 dias de viagem, daquele mestre Mathias Rapfael Ferreira, e dono Manoel Jozé Ricardo com carga de 202 cativos vivos, e 3 mortos (...).

Termo de visita dada ao Brigne Action vindo da Costa da Mina

Aos 16 de abril de 1827 nesta Cidade da Bahia, a bordo do Brigne Action vindo da Costa da Mina pela Ilha de Príncipe com 56 dias de viagem, daquele mestre

18 PIMENTA, Tânia Salgado. Artes de Curar. Um estudo a partir da Fisicatura-Mor no Brasil do começo do século XIX. Dissertação de Mestrado. UNICAMP, 1997. p 86.

${ }^{19}$ Ver o esboço das condições de trajeto nas naus negreiras na obra de Manolo Florentino, intitulada "Em Costas Negras".

${ }^{20}$ Fontes extraídas do Arquivo Municipal de Salvador - Bahia. Termos de visitas às embarcações de $\mathrm{n}^{\circ} 003$, 008 e 017 . O texto se manteve transcrito na íntegra, mantendo a sua forma original de escrita. 
Jozé (...) Almeida, e dono commigo Jozé de Carvalho com carga de 220 cativos vivos (...).

Provavelmente a demora da viagem tinha influências significativas no estado de saúde da população cativa. A delonga aumentava o tempo de exposição às más condições da viagem e estas circunstâncias de fragilidade os debilitavam. Isto é diferente de conceber as perdas relacionadas à população escrava como uma predisposição natural a certos tipos de moléstias. Outro aspecto importante indicado nesses termos de visita é o tipo de povos africanos que vinham da África para a Bahia. A documentação inclui termos de algumas embarcações que saíram da Angola e da Costa da Mina com destino à Bahia. Estas observações apontadas são relevantes na medida em que trazem de forma explícita dados como os dias do percurso de viagem e também o índice de mortes.

Tabela de controle de embarcações (saída e chegada) - 1825-1828*

\begin{tabular}{|l|l|l|}
\hline Navio & Saída & Chegada \\
\hline Bergantim Cerco & Costa da Mina & Bahia \\
\hline Bergantim S. Domingos & Angola & Bahia \\
\hline Bergantim de S. A. R. Santo Antonio Rey & Angola & Bahia \\
\hline Brigne Nossa Senhora da Guiné do Bom Caminho & Costa da Mina & Bahia \\
\hline Curveta Perola Africana & Costa da Mina & Bahia \\
\hline Brigne Socorro & Costa da Mina & Bahia \\
\hline Bergantim Felicidade & Costa da Mina & Bahia \\
\hline Bergantim America Portuguesa & Costa da Mina & Bahia \\
\hline Bergantim São Jozé Diligente & Costa da Mina & Bahia \\
\hline
\end{tabular}

Fonte: Dados de inspeção e cartas de embarcações. Documentação do Arquivo municipal da Bahia/Salvador $1825-1828$.

\section{Esboços das principais doenças nas embarcações negreiras}

No percurso dos navios negreiros, diversas moléstias ficaram conhecidas como doenças africanas. Justamente por acometer em sua maioria os cativos nesse processo de viagem, apesar de atingir também os membros da tripulação do navio, afirmou-se que elas 
eram mais propícias aos africanos. A predominância desse tipo de pensamento fez surgir todos esses estereótipos negativos em relação à saúde dos africanos e seu contato com o meio, e torná-los responsáveis por uma série de doenças.

Numa análise inicial dos termos de visita às embarcações pode-se notar a incidência de doenças apresentadas naquelas que foram pesquisadas. As mais abordadas foram: bexiga, escorbuto, sarnas escorbúticas, bobas, sarnas boboticas. Doenças ocasionadas pelo envolvimento de variados fatores, como a má alimentação, o cansaço físico, as condições climáticas e a aglomeração do número considerável de indivíduos em contato.

Tabela de controle de embarcações - 1825-1828*

\begin{tabular}{|l|l|l|l|}
\hline Navio & Cativos vivos & Cativos mortos & Principais doenças \\
\hline Bergantim Cerco & 202 & 3 & Sarnas escorbúticas \\
\hline Bergantim S. Domingos & 402 & 62 & Bexiga \\
\hline $\begin{array}{l}\text { Bergantim de S. A. R. Santo Antonio } \\
\text { Rey }\end{array}$ & 70 & 20 & Bexiga \\
\hline $\begin{array}{l}\text { Brigne Nossa Senhora da Guiné do } \\
\text { Bom Caminho }\end{array}$ & 301 & 6 & Sarnas escorbúticas \\
\hline Curveta Perola Africana & 233 & 10 & Sarnas escorbúticas \\
\hline Brigne Socorro & 331 & 9 & Escorbuto, bobas \\
\hline Bergantim Felicidade & 340 & 5 & Sarnas boboticas \\
\hline Bergantim America Portuguesa & 293 & 12 & Sarnas boboticas \\
\hline Bergantim São Jozé Diligente & 264 & 2 & Sarnas boboticas \\
\hline
\end{tabular}

Fonte: Dados de inspeção e cartas de embarcações. Documentação do Arquivo municipal da Bahia/Salvador $1825-1828$.

Nas entrelinhas dos documentos consultados, esta situação de agravo de doenças na população africana se expressa como algo novo que desafiava a administração colonial a procurar procedimentos e soluções. Como esse problema de maior vulnerabilidade dos povos africanos teria sido tratado pela política de saúde pública no período? Um primeiro contato com as fontes permite tecer algumas hipóteses.

Segundo Plácido Barbosa e Cássio Barbosa de Rezende, os serviços de saúde pública no Brasil começaram com a chegada de D. João VI e a família real (1808). As condições de saúde da população africana mereceram destaque no regimento da Provedoria-Mor, órgão criado pelo governo cuja responsabilidade baseou-se no policiamento da saúde nos portos. Conforme justificativa de sua alteza:

Tendo considerado ao muito que interessa o bem público e o particular dos meus fieis vassalos na construção da saúde pública, devendo haver todo o zelo, 
cuidado e vigilância em que ela não perigue por contágio, fiscalizando o estado de saúde das equipagens das embarcações que vem de diversos portos, obrigando-se a dar fundo em mais distâncias, as que saírem dos que são suspeitos de peste ou de moléstias contagiosas, e demorar por algum tempo, os que nela se transportaram ${ }^{21}$.

A princípio, a posição do governo não sugere disposições para resolver os problemas de saúde dos(as) africanos(as). Uma primeira consulta ao regimento da Provedoria parece confirmar a suspeita de que as más condições de saúde da população africana passam a ser incorporadas à agenda da saúde pública na medida em que os males que acometiam esta população eram vistos como potenciais agentes causadores de epidemias. Fazia parte dos procedimentos legais da Provedoria que os negreiros fossem vistoriados, ou seja:

\footnotetext{
No ato da visita se determinarão os dias que cada um desses navios deve ter de quarentena, conforme as moléstias que trouxer, mortandade que tenha havido, e mais circunstancia que ocorrerem; porém, nunca terão de quarentena menos de oito dias, em que os negros estejam desembarcados, e em terra (...) Acontecendo aportar na Capitania da Bahia e nos mais portos deste Estado do Brazil, alguma embarcação que tenha sahido do porto onde haja notícia ou suspeita de peste, não poderá alli fundear, mas será constrangida a vir fazer quarentena ao Lazareto da Boa Viagem desta Corte: deverse-lhe-á porém prestar todos os socorros e refrescos que precisar para poder seguir viagem, como a humanidade exige, e com as cautelas praticadas em semelhantes $\operatorname{casos}^{22}$.
}

$\mathrm{Na}$ Bahia, uma consulta parcial das fontes da Provedoria-Mor permite perceber que, na prática, as ordens do governo nem sempre eram cumpridas. Embora as visitas feitas por este órgão tenham identificado muitos casos de africanos(as) mortos(as) ou doentes nas visitas de saúde por embarcação e, portanto, necessitados de quarentena, isso não significou acesso ao tratamento adequado ou que lhes era de direito. Nos registros de visitas foi possível identificar conflitos entre guarda-mor e capitão dos navios em consequência das visitas de saúde, resistências à apresentação da carta de saúde ou encaminhamento dos doentes identificados para a quarentena. O livro de receitas da Provedoria baiana mostra que todos os procedimentos - tanto visitas quanto quarentenas eram pagos pelo dono do navio, o que poderia dar margem a atos de corrupção.

${ }^{21}$ BARBOSA, Placido e RESENDE, Cassio B. de. Os Serviços de Saúde Pública no Brasil de 1808 a 1907. Rio de Janeiro: Imprensa Nacional, 1909. Vol 1 e 2.

22 BARBOSA, Op. cit, p. 7. 
Um exemplo de situação cotidiana das visitas de saúde é o da Curveta São Joaquim, vinda de Angola. O registro desta visita data de 24 de março de 1807. Aliás, tratava-se de uma segunda visita, a mando do governador em ex-ofício. Conforme exame mais detalhado, realizado pelo Provedor de Saúde Ignácio Mattos Telles de Menezes, depois da primeira visita haviam morrido 60 africanos, e 22 ainda se encontravam acometidos de bexiga, marasmo, moléstia dos olhos e outras doenças. Este exemplo mostra que nem sempre o registro das condições de saúde das embarcações poderia corresponder aos fatos ou mesmo trazer soluções aos problemas ali apresentados. No livro de registro de visitas às boticas de várias embarcações, encontra-se uma série de multas conferidas pelo Físico-Mor, o que indica ter sido comum as boticas dos negreiros não apresentarem boas condições de atendimento ${ }^{23}$.

É visível nas fontes a preocupação com o isolamento da população africana atingida por doenças, com o interesse de proteger os demais da contaminação. As medidas de proteção idealizadas deveriam ser tomadas de acordo com o grau e o tipo de epidemia. Durante o período de quarentena se daria procedimento aos exames. Os cativos que por ventura fossem identificados sem condições para o desembarque em terra seriam conduzidos pelo Alcaide do Senado para os Sítios do Monferrada ${ }^{24}$. Conforme Manoel Vieira da Silva ${ }^{25}$ :

\begin{abstract}
Trata-se por ora de mostrar a necessidade de um lazareto onde desembarquem os pretos, e estes façam quarentena, que chegam no estado de saúde, até que se conheça, que eles estão livres das moléstias de que pode haver suspeita, bastando para estes o intervalo de oito dias: essa demora não pode fazer-se com utilidade a bordo das embarcações em razão da falta de asseio, de tratamento, e grande número de indivíduos, que a ambição obriga a juntar em um curto espaço.
\end{abstract}

Ao consultar Betânia Figueiredo é interessante notar que ela faz referência aos sintomas, mas não problematiza o diagnóstico. A doença escorbuto é um típico exemplo. Seu diagnóstico causou divergências de ideias no meio médico. Para o século XVII, na concepção de Alencastro (2000), o escorbuto estava relacionado a uma carência alimentar e

\footnotetext{
23 Arquivo Municipal de Salvador. Livro de visita às embarcações vindas da África (1802-1829) e Livro de Visita de Saúde as Embarcações Em Terra (1811-1828).

${ }^{24}$ Referência ao local onde acontecia o recolhimento dos enfermos com moléstias consideravelmente graves. Diante do contato com as fontes e as referências bibliográficas estudadas até o momento, não foi possível obter informações mais detalhadas e esclarecimentos acerca do mesmo.

25 Ver Reflexões sobre alguns dos meios propostos por mais conducentes para melhorar o clima da cidade do Rio de Janeiro, 1808.
} 
à insuficiência de vitamina C. Já para relatos de viagens trazidos no trabalho de Diana Maul de Carvalho ${ }^{26}$, embora a viagem de Vasco da Gama não tenha registros de escassez ou insuficiência de alimentos, a incidência de escorbuto foi constatada na embarcação. De acordo com essas constatações é imprescindível notar incertezas e imprecisões que nortearam este conjunto.

\section{Conclusão}

Pensar as práticas de cura na primeira metade do século XIX é compreender que entre os espaços e serviços de saúde havia embates e conflitos. Houve a necessidade da reafirmação de conhecimentos e ocupação de espaços, pois a própria hierarquização entre os ofícios contribuía para esta estrutura. Neste processo de reafirmação há a delimitação de dois grupos atuantes: a medicina oficial e a medicina popular. O primeiro se respalda no campo mais científico direcionado a partir de pensamentos concebidos nas instituições médicas ou acadêmicas. O segundo movimenta os conhecimentos específicos do cotidiano da cura. Segundo Flávio Edler ${ }^{27}$, a este último foram atribuídas a ineficiência, a ignorância e até mesmo a superstição, e as suas atividades foram tratadas de modo pejorativo pelo discurso médico.

A atividade de sangrador não foge a essa regra, e foi perseguida assim como as demais artes de curar. A Fisicatura-Mor tentou reduzir aos poucos o seu espaço de atuação na sociedade, por meio da exigência da oficialização e legalização de seu ofício. Isso de maneira alguma significou que esses sujeitos deixaram de ser procurados pela população e até mesmo por autoridades do governo colonial e senhores de engenho, ou que tiveram o seu mérito e respeito deteriorados. No entanto, a carta de licença representava um empecilho, ou seja, um pré-requisito fundamental, algo que provavelmente dificultava consideravelmente o ritmo de trabalho dos sangradores. Nem todos os que continuaram atuando como sangradores possuíam uma licença em mãos. Portanto, poderiam ser autuados pela fiscalização. Mas isto não significou, em hipótese alguma, a extinção da categoria, que até os dias atuais ainda sobrevive em diversos cantos do mundo.

\footnotetext{
26 A discussão abordada está presente no artigo "Doenças dos escravizados, doenças africanas?", de Diana Maul de Carvalho.

27 Flavio Coelho Edler, pesquisador da COC - Fiocruz e escritor do artigo "A medicina Brasileira no século XIX: um balanço historiográfico”.
} 
Essas práticas de cura sempre farão parte da construção da memória histórica dos povos africano e brasileiro. Sua atuação conviveu e convive com aquela medicina dita científica. Obviamente, existiram e ainda existem divergências e conflitos, mas também aprendizado e circulação de conhecimentos, que impulsionam o aprimoramento do saber e fazer médico. Deste modo, supomos, a partir desta análise inicial, que os sangradores africanos durante o século XIX contribuíram para a concretização de uma assistência em saúde no cotidiano da sociedade.

\section{Referências}

1. ALENCASTRO, Luiz Filipe de. O trato dos viventes. Formação do Brasil no Atlântico Sul. Formação do Brasil no Atlântico Sul Séculos XVI e XVII. São Paulo: Cia das Letras, 2000, p. 127.

2. BARBOSA, K. V. O. Escravidão, mortalidade e doenças: novas dimensões da experiência negra, século XIX. In: Encontro Regional de História. São Paulo: Anpuh, 2008.

3. CHALHOUB, Sidney. Cidade Febril: cortiços e epidemias na Corte Imperial. São Paulo: Companhia das Letras, 1996.

4. ㄴ. Visões da Liberdade: uma história das últimas décadas da escravidão na corte. São Paulo: Companhia das letras, 1990.

5. CHALHOUB, Sidney, Vera Regina Beltrão Marques, Gabriela dos Reis Sampaio, Carlos Roberto Galvão Sobrinho (org.). Artes e ofícios de curar no Brasil: capítulos de história social. Campinas: Ed. da Unicamp, 2003.

6. DEBRET. Viagem pitoresca e histórica ao Brasil. Belo Horizonte / São Paulo: Ed. Itatiaia / Edusp, 1989.

7. EDLER, F. C. A medicina brasileira no século XIX: um balanço historiográfico. Asclépio - vol. L-2, 1998, p. 169-186.

8. FIGUEREDO, Betânia Gonçalves. "As doenças dos escravos: um campo de estudo para a história das ciências da saúde”. In: Uma história brasileira das doenças, v. 2 - Dilene Raimundo do Nascimento, Diana Maul de Carvalho, Rita Cássia Marques (org.); autores Anna Beatriz de Sá Almeida et. al. - Rio de Janeiro: Mauadx, 2006. p. 252-277.

9. FLORENTINO, Manolo. Em costas negras: uma história do tráfico de escravos entre a África e o Rio de Janeiro (séculos XVIII e XIX). São Paulo: Companhia das Letras, 1997. 
10. FLORENTINO, Manolo; RIBEIRO, Alexandre Vieira; Silva da, Daniel Domingues. Aspectos comparativos do tráfico de africanos para o Brasil (séculos XVIII e XIX). Afro-Ásia, no 031, p. 83-126.

11. FREITAS, Octávio de. Doenças africanas no Brasil. São Paulo: Cia Nacional, 1935.

12. PARÉS, Luis Nicolau. A formação do Candomblé: história e ritual da nação Jeje na Bahia. São Paulo: Editora da Unicamp, 2007.

13. PIMENTA, Tânia Salgado. As artes de curar — um estudo a partir dos documentos da fisicatura-mor no Brasil do começo do século XIX. Dissertação de mestrado. Campinas: Unicamp, 1997.

14. PORTO, Ângela de Araújo. Doenças e escravidão: sistema de saúde e práticas terapêuticas. Rio de Janeiro: Casa de Oswaldo Cruz - Fiocruz, 2007.

15. SAMPAIO, Gabriela dos Reis. Nas trincheiras da cura: as diferentes medicinas no Rio de Janeiro imperial. Campinas: Editora da Unicamp, 2001.

16. THOMPSON, E. P. Costumes em comum: estudos sobre cultura popular tradicional. São Paulo: Companhia das Letras, 1998. 